\title{
Methods for assessing the impact of research on innovation and development in the agriculture and food sectors
}

\author{
Ludovic Temple $^{1}{ }^{*}$, Estelle Biénabe ${ }^{1}$, Danielle Barret ${ }^{2}$ and Gilles Saint-Martin ${ }^{2}$ \\ ${ }^{1}$ Cirad Umr Innovation, Montpellier, France \\ ${ }^{2}$ Cirad-Dgdrs, Paris, France \\ *Corresponding author email: ludovic.temple@cirad.fr
}

\begin{abstract}
The need for technological transition and the context of the privatization of public research funding both challenge the evolution of methods to assess the impact of research in the agricultural and food sectors. We analyze this evolution through a literature review and an examination of a range of case studies on research completed in developing countries. In the first part, the results stemming from the former analysis question the controversies raised by quantitative approaches. In view of these controversies, we then examine the methodological innovations taking place in a qualitative approach. A survey of case studies ultimately helps to characterize the strategic resources that research generates with a view to improving its impact on innovation and development.
\end{abstract}

Keywords: innovation system, technological trajectory, research evaluation, impact assessment, agricultural research for development

\section{Introduction}

Since 2000, the multiplication, acceleration and convergence of various crises (social, economic, environmental and energetic) have seriously put at risk globally our global economic development model. These crises call for a change of technological paradigm for meeting the Millennium Development Goals and tackling unequal development (McIntyre et al. 2008; Sumberg, Thompson, and Woodhouse 2013; ONU 2015), while research has a key role to play in achieving this paradigm change. Recent decades were marked by a decrease in public funding both around the world and in particular in development countries. This has led to the privatization of investments in research with the growth of foundations, as well as an increasing share of funding from globalized companies that govern global value chains (Carlson 2006; Pietrobelli and Rabelloti 2011). This move has gone together with increased pressure on research accountability. Concurrently, the methodological approaches for assessing the relationship between public research activity, innovation processes and mechan-isms of development are increasingly under scrutiny and being questioned. Conventional economic indicators of impact productivity, economic growth and financial returns on investment - are increasingly challenged on two different levels. First, these indicators poorly integrate the environmental and social dimensions of development. Second, they poorly take into account the diverse development needs of different societies.

This gap between societal expectations and funding structures for public research has fuelled the need to renew methods for assessing the impact of research in agriculture and food, in particular within international institutions (De Janvry, Dustan, and Sadoulet 2011). We aim to contribute to this by examining and deriving lessons from the trajectories of, and issues raised by, these methods, as well as by proposing innovative concep-tual insights.

Building upon a literature review, the first part of this paper analyses how the methods for assessing the impact of research in this area have evolved since the 1970s, highlighting the main issues faced by these approaches and the controversies raised (Woodhouse 2010). In light of these controversies, the second part examines the recent methodological adjustments to quantitative and qualitative evaluation methods. Finally, in the third part, we present the application of a qualitative approach to a range of case studies conducted in developing countries and show how this can contribute to improving methodological frameworks for research impact assessment. We make the hypothesis that methods analyzing causality between research and development can generate knowledge leading to innovation in different development strategies.

Conventional methods for assessing the impact of agricultural research

Quantitative methods to assess the impact of agricultural research

The sociology of science refers to the impact assessment (IA) of research as the most comprehensive study of science and society (Callon and Foray 1997). Two epis-temological perspectives are identified in this field. The first presupposes the autonomy of scientific research in relation to other fields (political, social, cultural). The second sees science as a product of social, political and entrepreneurial interfaces (Bozeman 2011). The first stance predominantly structured international research in the agriculture and food sector during the green revolution between the 1960s and 1990s. Supported by a set of insti-tutions, ${ }^{1}$ this research primarily used linear and 'diffusio-nist' innovation models (Parayil 2003). To assess the impact of research on development, it privileged the use of quantitative analytical methods in the design of these models. When applied to investments in public research, these methods can be distinguished depending on whether they aim to show effectiveness (the relationship between means and results) or efficiency (the relationship between means and objectives). The first type combines monetary quantitative assessment approaches (Maredia 
and Raitzer 2010), while the second builds on studies that quantify the relationships between research investments and macro-development indicators: economic growth, productivity or more microeconomic analyses (Nyemeck and Nkamleu 2006).

The monetary assessment of the effectiveness of research: monetization of the impact of research

Cost/benefit analysis methods became popular in the economic literature in the 1950s and were introduced in development economics in the '60s. Initially often mobilized in ex-ante assessments, they were subsequently used to assess ex-post the financial return of agricultural research investments in different contexts. Challenged by the difficulty of translating impact on development into 'monetary benefits' and criticized for the elevated sensitivity of results to low data variation or institutional contexts of their development (Kingwell 1999), these approaches shifted towards surplus methods in the 2000s. 'Surplus' methods are based on microeconomic theoretical prin-ciples of balancing supply and demand (Alston, Norton, and Pardey 1995). The logical framework first experimen-tally measures (through research stations or peasant trials) how a research investment-related invention (hybrid, new molecule, etc.) generates an increase in returns. Studies on the adoption rates of invention at different scales then evaluate the areas that potentially benefit from these inven-tions. Using experimental return gains, they extrapolate increases in production at the national level resulting from the studied inventions. These increases shift the supply curve in microeconomic models and are therefore translated into economic surpluses for the producer and the consumer that can be mathematically assessed (Arega et al. 2013). These shifts in the curve are con-sidered as capturing producer and consumer benefits using integral calculations.

By adding these benefits to investments, financial assessment indicators such as 'Net Added Value' and 'Internal Rate of Return' are then calculated. These models thus provide a monetary assessment of social surplus. They are based on the microeconomic rationality hypothesis that underlies the Walrasian general equilibrium theorems. Published works based on these methods show the high rate of financial return on investment in agricultural research (Alston et al. 1995; Heisey et al. 2010).

\section{Macroeconomic meta-analyses}

The persistence of poverty, the increasing number of people affected by poverty and the inertia of productivity ratios in the agricultures of 'least developed countries' (LDCs) have been challenging the validity of previous microeconomic modelling results. Is difficult to explain the discrepancy between increased profitability of research investments and technological inertia, together with stag-nating productivity in terms of yield and innovation. in sub-Saharan Africa (Dorin, Hourcade, and Benoit-Cattin 2012).

Two sets of quantitative IA works propose answers to this issue. The first is based on econometric approaches that reveal structural determinants of production. These explain the difference between potential and actual achievements of technical change in agriculture (Renkow and Byerlee 2010).

The second consists of meta-analyses for assessing monetary impacts and explaining the socio-institutional conditions for achieving good results (Alstom 2010). Both sets converge to highlight the importance of socioinstitutional environments and how their variability (conditions for access to productive and cognitive resources) plays a central role in the relationship between research and development (Pal 2011). However, they hardly explain how research contributes to the structuring of these institutional environments. This is at the heart of the proposed framework developed in the last part of this paper.

Major quantitative methods: limitations and issues Internal methodological limitations

The difficulties in capturing externalities and the long term: Public research is sought out to accelerate innovation in view of the Millennium Development Goals (ONU 2015). It must address the complexity of meeting economic, environmental and social goals that are not necessarily compatible. Cost/benefit analysis methods, as well as more generally quantitative methods, are well adapted to the specific cases where research proposals are directly transformed into increased production, the benefits of which can be elicited through market valuation. However, these methods do not count the impacts on development related to the externalities of research outputs (positive or negative) for two separate reasons. The first is the significance of systemic externalities associated with interactions between the different types of identified outputs (i.e., technological, institutional, organizational) that research investments can generate. These externalities, featured in land conflicts, inequality, and health and labour conditions, can trigger 'hidden' costs or benefits that should be accounted for. The second is the time lapse between a research result, its appropriation and its use, as well as the consequences of this result that contribute to increasing the range of extern-alities and limiting the capacity to account for these externalities at an early stage after research activities are conducted.

A true consideration of externalities is difficult in Africa. Several factors explain this, including the lack of statistical information, laboratories for analysis (of pollution residue) and institutions checking against fraud of international social and environmental standards. For negative externalities, the most well known in agriculture is the impact of intensive pesticide practices on human health (De Bon et al. 2014), water quality and biodiversity, which bring about long-term hidden costs (Mostafalou and Abdollahi 2013). With regard to positive externalities, the effects on increasing yields and the rise or creation of paid work is often highlighted.

As an illustration, the cost/benefit evaluation of a genetically modified (GM) variety can display a positive balance for multinational firms or small producers in the short term. In the long term, however, the variety may diminish biodiversity (Fok and Xu 2010) or lead to 
social exclusion by constraining the producers' farming choices and resilience (Arza and van Zwanenberg 2014).

Concerns about the methodological reliability of the deployed data: Regional extrapolation of data obtained from experimental trials to measure adoption is contestable. In fact, the conditions for obtaining in-station plot returns controlled by experimental protocols are hardly reproducible. The reliance on yields calculated in monoculture raises large methodological uncertainties when applied to the widely diverse agrarian realities that dominate farming systems, particularly in the developing world. Furthermore, the notion of adoption is considered at one point in time, not dynamically. Hence, it does not take any reversal - such as abandonment or withdrawal of a new variety a few years later - into account (Glover, Sumberg, and Anderson 2016). Finally, the avail-ability or reliability of usable secondary returns is insuffi-cient in developing countries.

The question of attribution and temporality: In order for socio-economic actors to mobilize research outputs, investing in innovation policies (outreach programmes, training, transfers, loans, etc.) is required. IA, therefore, needs to integrate other contributions. However, the attribution of roles between researchers and others by the researchers themselves makes these impact assessments contestable. Furthermore, as already mentioned above, and as is widely recognized, difficulties of attribution increase with the time lapse between the conducted research and observed changes. Moreover, some discoveries or knowledge may not have an impact, per se, but do add to a reservoir of knowledge that can initiate change at a later date.

Controversies in the theoretical foundations of mobilized methodologies

The underlying neo-classical assumptions: Beyond the critiques exposed above, issues also arise from the theoretical hypothesis underlying quantitative methods. The indicator of benefits is measured as the monetary value attributed to the movements of supply and demand curves. However, these models are based on a theoretical neo-classical microeconomic frame of reference. They lie on two substantive hypotheses of the Walrasian equilibrium, according to which the value is determined by indi-vidual utility curves and where the sum of individual interests leads to collective interest. The relevance of these hypotheses is criticized in societies where resource management depends on collective cohesion and where the securing of living conditions relies on institutions other than the market (Omamo and Lynam 2003). The worldwide general reliance on these methodological frames implicitly results in uniformly imposing one form of rationality to different human societies that are specifically embedded culturally, politically and geographically and one value system as a universal frame of reference for orientating technology choices (Sabourin 2014). Most works on current contemporary environmental and social imbalances require taking another look at the unity of this economic rationality. A second transversal criticism rests on a linear model of the innovation process.
The linear model of the innovation process: Since World War II, the linear pattern of innovation has been widely disseminated in agriculture and food. In this pattern, scientific research is seen as the centre of knowl-edge creation; knowledge is then transferred to the beneficiaries/users through specialized organizations (consulting, outreach groups, etc.). It is the transformation of knowledge into something new (products, processes, artefacts, organizations, standards) that is responsible for the transition from invention to innovation, with the market filter selecting successful innovations from the per-spective of its operation. This model of innovation has in particular structured the technological diffusion's transfers of the green revolution.

The focus on transferred 'finished products', such as hybrid varieties, ${ }^{2}$ in agricultural research studies goes along with and reinforces the primacy of the linear model of innovation. This focus induces methodologies adapted to this type of selected priority outputs (e.g., research invents a hybrid that it transfers) and to the linear model of innovation associated with it. These syner-gies strengthen an industrial biotechnological governance of innovation processes in the agricultures of developing countries. The diversification of works on other outputs, such as integrated pest management control methods, intercropping and multiplication of plant material (Temple et al. 2015), opens other methodological perspectives.

The previous innovation model has generated successes measured by conventional productivity indicators. Today, that model is challenged in its ability to take into account environmental and social factors and diversify evaluation criteria. The linear innovation model evolved into the 'interconnected chain' model; nowadays, it is becoming a systemic model of innovation (Laperche, Uzunidis, and Tunzelmann 2008). The 'impossibility' of finding direct causal relations between research input and development is now largely acknowledged. Further-more, the need to break down the effects of research is also acknowledged (regardless of how they are measured) through a precise understanding of the process that may or may not lead to an impact on development.

Below, we analyze the main methodological innovations in assessing the impact of research on development by relating them to the realities observed in southern countries' agricultures.

\section{Methodological diversification in agricultural research impact assessment}

In view of the limitations of conventional evaluation methods, two approaches guide the methodological evolution of agricultural research. The first consists of revisiting quantitative approaches to address the main critiques that they face, which entails adapting the methodological corpus while maintaining the theoretical fundamentals. The second approach builds on the institutional renewal of innovation economics around the concept of an innovation system (Clark 2002; Touzard et al. 2015). It offers a more radical break away from the linear inno-vation model (Klerkx, van Mierlo, and Leeuwis 2012), in particular restructuring qualitative methods in terms of 
the impact pathway (Douthwaite and Gummert 2010). Furthermore, it uses instruments of measure, but not necessarily those of quantification. We will now examine these two approaches, which are guiding a number of research programmes and projects (Gaunand et al. 2015).

Experimental evolution of quantitative methods: randomized trials

The current evolution firstly consists of a change in focus, though it seems no more than a semantic change. The quantitative method no longer assesses the impact of research on development per se, but rather that of innovation on development. Innovation is, however, reduced to the mere implementation of a technical or organiz-ational change resulting from a research activity. It does not deal with the conditions of its emergence. The speci-ficity and diversity of research contributions are still viewed as a 'black box'. Considering innovation and research in that simple way allows for applying exper-imental economics based on randomized trials, which were originally intended and designed for medical science (Duflo, Glennerster, and Kremer 2006). This use of experimental economics also results from a transfer of methods for evaluating development projects. However, the characteristics of development project products (e.g., the 'effect of the use of treated/untreated mosquito netting on malaria in children) are not the same as those of research (Naudet, Delarue, and Bernard 2012). The system in which the changes associated with the inno-vation have to be assessed is compared to a counterfactual situation that has not benefited from research intervention; this latter situation is used as a control group or environ-ment, just like those practised by the life sciences, with a randomized allocation of subjects between the group benefiting from the innovation and the control group.

The evolution of these methods consists of improving the scientific rigour of the comparison and leads to the econometric complexification of the tools (Joly et al. 2015). Applying these methods requires sophisticated and specialized skills as well as databases, which increase the implementation costs. This limits the use of these methods by researchers of developing countries. It also reinforces the scientific control of impact assessments by research institutions.

The critiques of the use of these methods include two other dimensions. The first concerns the lapse in time after an investment that changes the relative prices and engen-ders risks. Hybrid cocoa or citrus plants (Dury and Temple 1999) can increase yields in the short term. Yet, as they are often more sensitive to local disease, these also generally increase yield variability, and therefore the income or price instabilities, which put small vulner-able farmers in difficult situations.

The second relates to the contextual character of the results and to the conditions of the generalization of these results. Indeed, technological externalities (spillover effects) or increasing/decreasing adoption returns can modify results (De Janvry, Dustan, and Sadoulet 2011). The rise in the adoption rate of a new technical process (e.g. grain mill) adapted to local needs increases the profit-ability of repair services (expertise, spare parts), which, in turn, lowers the prices for these services. The new process thus becomes more profitable. These effects that take time to develop are most likely not captured in the experiment. Conversely, the homogenization of technical itineraries for high-yield varieties could increase pest pressure and thereby the use of pesticides. In the long term, these pes-ticides degrade soil fertility and the initial profitability cal-culated at the 'start' of innovation. Finally, the high sensitivity of cost-benefit analyses to slight price vari-ations or technical coefficients explains the criticism of their use in long-term research impact assessment (Matthew and Rafols 2015).

Qualitative diversification of methodologies: the evolutionist contribution of innovation systems

Evolutionist works on innovation (Nelson and Nelson 2002) from the 1980s increased use of the concept of an 'innovation system', especially in international agricultural research institutions (Nederlof, Roling, and Van Huis 2007; Klerkx, Van Mierlo, and Leeuwis 2012). This renewal has strengthened and diversified the understanding of systemic dimensions of innovation in the agri-culture and food sector. Innovation is borne of systemic interactional processes that generate and hybridize differ-ent forms of knowledge (i.e., scientific and tacit knowl-edge, as well as local know-how) and structure the processing and selection conditions of such knowledge into innovations. Research is one 'actor' among others that generates specific resources in terms of knowledge and skills. Innovation is recognized as being both multifa-ceted and complex to define. It includes the emergence of new technologies, organizations, ways to produce, net-works, indicators and ways of thinking about develop-ment. The 'black box' left unexplained by quantitative approaches then itself becomes a subject of knowledge to be explained.

One dominant methodological focus consists of characterizing the institutional arrangements that structure the interactions between the actors that underpin inno-vation processes. These intervene both in the co-con-ception phase that generates 'novelties' in terms of knowledge, information, standards, technical artefacts and organizations, as well as in their social implemen-tation and economic validation. The phases of emergence, adoption and dissemination are no longer sequenced line-arly. Their continuous retroactions are accounted for. These approaches clarify the 'manufacturing' of relation-ships between research activities and their consequences on development. In line with this conception, the term of 'attribution' is replaced by that of 'contribution' of research to innovation processes.

Another differentiating factor compared with conventional quantitative approaches concerns the grounding into an institutionalist theoretical framework. In this broader framework, economic substantial rationality is only one type of rationality among others. It is integrated but is no longer exclusive. This change is at the origin of a double epistemic and methodological break.

From an epistemic point of view, the challenge is no longer to quantify the relationships between research and development or between innovation and development. 
Rather, the challenge is to assess the building process between research and development and to interweave these processes with the development priorities socially expressed in their various forms. The issue is no longer to apply blindly conventional indicators (productivity, effi-ciency, income) as measures of development goals, nor is it to 'reveal' impacts based on predefined environmental, social and economic dimensions. The question is that of assessing how research generates or takes part in processes that address topical development issues, such as poverty reduction, consistency and social justice, protection of bio-logical and cultural diversity, and climate protection (Bozeman 2011). From a methodological point of view, this means conceptualizing innovation as a systemic process.

The CGIAR (Consultative Group for International Agricultural Research) operated this break incrementally over the last decade (Hall et al. 2003) and largely contributed this way to a specific trajectory and methods, referred to hereafter as 'impact pathway approaches' (Douthwaite and Gummert 2010). These approaches build upon the institutional framework to explain the critical factors in organizing interfaces between actors in the research process that produce the reality of impacts and their nature. These factors are identified as being situated between research institutions and firms, whether global (biotech firms) or localized (small enterprises). Firms and scientific research symmetrically generate knowledge, technical artefacts or processes at the sources of inventions and implement mechanisms for capturing and exploiting available cognitive resources in agrarian societies (Vanlo-queren and Baret 2009).

The other methodologic option (Nederlof, Roling, and Van Huis 2007; Röling 2009) focuses its criticism on the linear conception of innovation governed by private entrepreneurial dynamics. Indeed, these meet the needs of their designers, but not necessarily rural societies' priority development issues or the specificities of locally available resources. The cursor of the impact assessment is placed on the emergence of processes that create interfaces between research institutions and social dynamics. It is a matter of inserting an institutional mechanism for respond-ing to the needs of sustainable development into the con-ditions of scientific knowledge production. The evolution of methodologies thus attempts to represent the diversity of the research-induced changes in terms of identifiable outputs and outcomes from an economic, environmental and social point of view.

These two trajectories of quantitative and qualitative evaluation express different perceptions regarding the functions of assessing the impact of research. They are compared through an analytical grid (Table 1).

This grid highlights the main differences and similarities at theoretical and methodological levels, and in terms of results. Impact pathway approaches are further analyzed below.

\section{Impact pathway approaches}

Impact pathway approaches are the main qualitative approaches in agricultural research for development. These approaches originally retain a linear structure of sequences, whereby research transforms inputs (investments, resources) into products (outputs); then, from these outputs, outcomes (results) are generated, which eventually result in impacts on development to be qualified. However, they further specify themselves according to their use either in ex-ante, in itinere or ex-post evaluations and according to the intention (i.e., monitoring

Table 1: Comparative analysis of methodological trajectories assessing the impact of agricultural research.

Conventional methodologies New methodologies

Relations of convergences and/or complementarities

Nature of the different Evaluation of linear causalities between research and issue

Method

Dominant interdisciplinarity

Relations of competition Theoretical frame of references

Results

Economic, social, environmental risks development or between innovation and development

Quantification tools

Econometric models

Experimental economics: randomized trial

Economist/Manager and Biotechnical Sciences reference

Walrasian optimized rationality of general equilibrium theorem

Diffusionist model of innovation or vortex model

Promoting technological transfers: north-south, biotechnological firms, agriculturalists

Homogenization of technological choices, strengthening of private governance (multinational) of innovation

Concentration of sources of innovation within

firms (scale economy)

Concentration of agro-industrial farms

Low taking into account of environmental, social or biodiversity risks, social exclusions
Dominant neo-classical economics frame of
Evaluation of interactionist process of creation of impacts on development

Measurement tools: multi-criteria analyses Systemic models of analysis

Participative and comprehensive investigations of case studies

Economist/Sociologist and Agronomic Sciences

Institutional economics frame of reference: Pluralities of rationalities Systemic model of innovation or constructivist

Promoting the implication of local knowledge in scientific orientations

Strengthening local innovation capacities according to the ecosystem

Slowing of innovation processes

Insufficient productive performance

Dislike for mobilization of knowledge advances offered by science 
and evaluation, communication, management) and institutions they serve. Used ex-ante, they can structure programmatic result-oriented research objectives and create the necessary frameworks for projecting the desired result. They are mainly used in CGIARs in itinere to pilot and possibly reorient research programmes according to the structure of the expected impact (Walker, Ryan, and Kelley 2010; Leeuwis et al. 2014). In other institutions, these approaches are used instead for ex-post evaluation (Gaunand et al. 2015). Reflecting on this ex-post use leads to diversifying the given definitions of 'outputs' and 'outcomes', and to questioning the initial linear phasing.

Generally, 'outputs' are defined as tangible products, services and knowledge developed by agricultural research in laboratories and field stations, increasingly within multi-stakeholder platforms. 'Outcomes' can be described through directly observable results at micro levels: plot or farm according to adoption rates. 'Impacts' are defined by the causal relationship estab-lished between these 'outcomes' and indicator changes at the meso-economic level in chains and territories, or at the macro level. Because this understanding is systemic, it is difficult to quantify with the usual assessment methods (Berriet et al. 2014).

Resources of research in partnership to activate the pathways of impact on innovation and development We applied the impact pathway approach to six case studies involving the same research institution in southern countries so as to explore innovations in agriculture and food sectors in the south. This exploration shed light on the specificities of resources that research in partnership generates. It related research contributions to the role of these resources in the transformation of outputs into out-comes and of outcomes into impacts.

The two first case studies concern methods that improve the production of yams in Haiti and plantains in Cameroon (Temple et al. 2015). The four others concern a vaccine against a small ruminant plague (Morocco), mango varietal collections (West Africa), a method of management consultancy (Burkina Faso), and a machine for post-harvest mechanization of local cereals (Senegal, Mali). These latter four case studies were conducted by a working group between 2010 and 2012.

All six case studies have been analysed using a grid with two main tools to characterize the impact pathway: a historical reconstruction of the innovation emergence and implementation (Boyer, Temple, and Scutt 2014; Temple et al. 2011) and an explanatory model documenting the events that structure the transformation of research inputs into outputs, outcomes and impacts to feed into the design of the impact pathway.

Building on a transversal analysis of these case studies (Eisenhardt and Grabner 2007; Yin 2014), we put forward the different types of resources that research contributes to over time in carrying out the transformation into the use of the knowledge and results that it generates in a develop-ment perspective (Table 2).

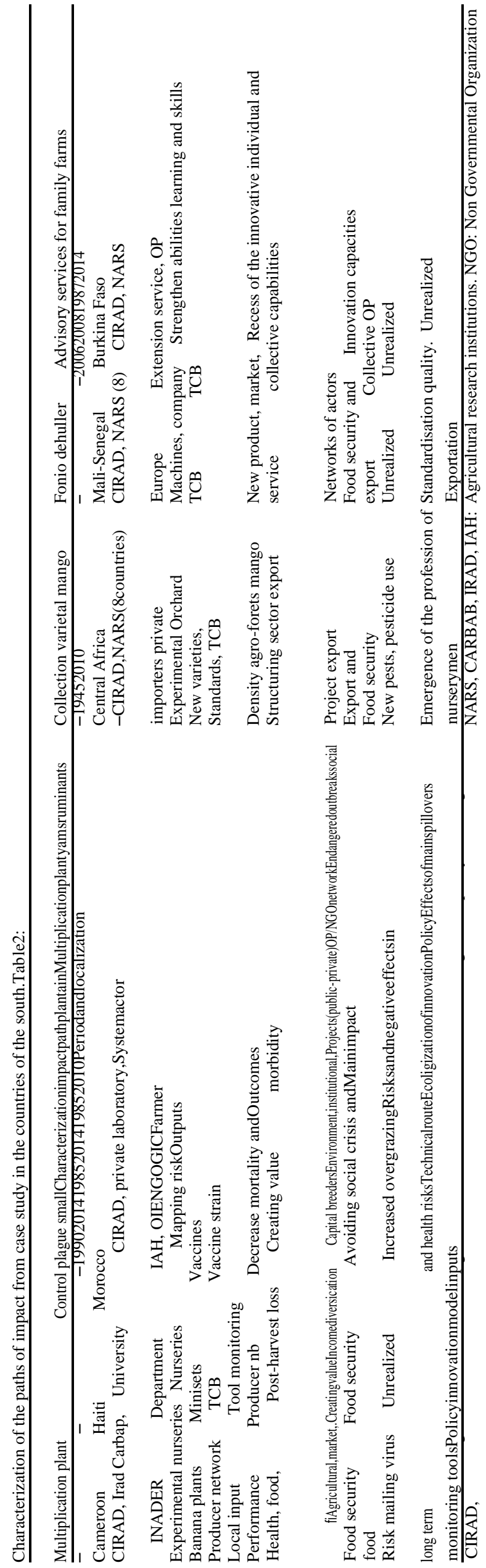


Systemic dimension of innovation for the development of southern countries

Institutional co-construction of innovation

All case studies show that the combination of research results is not generated by a single institution, but rather by a set. This set variably produces interactions between, on the one hand, research (international research centres, national research institutes, universities) and development institutions and, on the other hand, social (cooperatives, NGOs) or private (business) actors. This set of complex interactions symmetrically structures:

the emergence of knowledge, technical artefacts, processes and methods: propagation methods, hybrids, machines and consultancy;

the mechanisms that insert inventions into production systems and create the institutional, commercial and pol-itical conditions of their implementation.

This confirms the methodological illusion of intending to isolate the relationship between research investment and impact on development. Indeed, the trajectory of inno-vation generated out of this investment needs to be observed over a long time, generally more than 20 years. For example, building upon dissemination methods of Brazilian research findings in 1975, developments of planting material (suckers) for bananas in Cameroon in 1991 resulted in the adoption of those technologies in Haiti and Madagascar in 2013. Over this period, the struc-ture of the actor system associated with the different phases of the innovation process was not stable. Further-more, the links between the 1975 Brazilian research study and the improvement of living conditions for the populations of Haiti and Madagascar in 2013 cannot be quantified.

All case studies converge to show that the phase of transforming outputs into outcomes plays a central role in backing research investments on impact. Indeed, it is in this phase that the upstream creation of externalities seems to focus on the direction of research and downstream on the socio-institutional contexts. This creates consistency in the co-evolution between technological and institutional results that feed relationships between research activity and development mechanisms. The interactions that structure scientific knowledge are at the centre of the transformation mechanisms that characterize the impact pathways at the different phases.

Upstream dynamics build upon the taking into account of the tacit knowledge or know-how of rural societies on localized conditions (ecosystem) for developing outputs (these conditions may be constraints or opportunities). The creation of this information loop that is based on a partnership with national researchers accelerates the adap-tation of outputs to specific needs. In downstream dynamics, research is involved in the implementation of innovation support policies, i.e. development projects (public or NGO based) as well as legal and political tools such as standards and ownership rights that shape implementation and dissemination mechanisms. These research features can be made visible by identifying two interacting mechanisms, respectively: spillover effects and adoption returns.
Spillover effects and adoption returns: the centre of developing impact pathways?

Spillover effects refer to the spillovers of knowledge or technology related to the geographical concentration (local, regional) of the innovation system. They are some-times shaped by the emergence of localized or regional production clusters or systems. They may be based on intangible resources (information, knowledge, networks, skills) or collective actions through pooling equipment use, raw materials or services related to innovation. They may have an intentional dimension (resulting from political or strategic choices) or they may be unintended. The purpose of their identification is central to understand-ing and characterizing the resources that shape adoption mechanisms and contribute to increasing adoption returns. We show three case studies and the nature of these spillover effects.

Regarding the dissemination methods of plant material for plantains (Cameroon) and yams (Haiti), the use of a new planting material required improving collective knowledge on the mechanisms of plant growth from an ecosystem perspective. This led to major changes in crop management against diseases and pests. The associ-ated increase in returns boosted the demand for this new planting material (minisets and suckers) and the number of investors (firms, state companies) in these technologies. Enhancing the visibility of the impact of these technol-ogies on increased productivity through research has involved researchers in the development of national pro-jects to support the development of its technologies using international funding.

With respect to the local mango varietal collections that were established and used instead of external varieties, the development and then local appropriation of techniques in field stations led to the rise of private nurseries. These micro enterprises have been a vehicle for transferring these techniques to other local fruit varieties. Other examples of these spillover effects are shown in Table 2 .

Spillover effects could also generate secondary effects that modify the nature and intensity of economic impact. These secondary effects create opportunities or obstacles to the dissemination of innovation. A side effect of this is the building of capacities to learn and hybridize different forms of knowledge (scientific, technical, tacit) in an inno-vation process. These capacities are resources that consti-tute sociotechnical networks for disseminating innovation. In contrast, firms' patent filings on local resources (plants, processes) could deprive local farmers and entrepreneurs of the opportunity to independently appraise locally pro-duced biodiversity resources (Laperche 2009).

Because they were difficult to quantify without specific methodological protocols, these secondary effects were not referenced in the observed situations.

Spillover effects structure what is called 'adoption returns', which, depending on the situation or the period, could be increasing or decreasing. Adoption returns set up a positive or negative relationship, on the one hand, between the adoption rate and the efficiency of the relationship between inputs and outputs and, on the other hand, between outputs and outcomes. Adoption 
returns are therefore an element of the relationship between the outcomes and the impact. Their assessment requires the elaboration of specific methodological protocols.

As expected, significant methodological data collec-tion challenges were faced in capturing the different spil-lover effects and adoption returns in the six case studies. However, exploring these effects did allow us to shed light on the resources that research generates at the differ-ent stages in the process to transform outputs into out-comes and then outcomes into impacts. This led to the identification and characterization of the different categories of resources that play a key role in the contribution of research in partnership with impact generation.

Strategic resources generated by research for contributing to development

From a dynamic perspective, research contribution to producing and transforming different resources as part of the evolution of innovation processes leads to different types of capital formation and accumulation. These are the major assets through which research contributes in the long run to generating an impact. Building transversally over the varieties of studied cases, we categorized and classified them generically as social capital, human capital and sociotechnical assets (Figure 1). These types of capital can be mobilized in different configurations depending on the phases of the innovation process. The production of these capitals is simultaneously an input of processes that generates impact and by itself constitutes a contribution to development.
The characterization of the different forms of capital coproduced over the long term at different interfaces between stakeholders and at different steps of the impact pathway (inputs/outputs/outcomes/different-level impacts) allows for better comprehension of the nature of the research contribution to development. Distinguishing these three types of capital provides grounds for setting up an analytical grid and improving methods for the qualitative assessment of the impact of research.

\section{The formation of social capital}

What is captured with the formation of social capital (Pretty and Ward 2001; Georghiou 2011) is the creation of institutional resources: social networks, regional institutions, regulatory or social standards, and collective values that draw on and further create the necessary interactions for building partnerships. These partnerships that underpin multi-stakeholder innovation processes are central to the transformation of research knowledge and input into 'outcomes' - that is to say, into results appropriable by users. The various case studies characterize the frequent situations for creating these resources through research.

Social capital is created through multi-partner connections in research and development projects, as well as during different events or crises that give rise to productive networks of knowledge and innovations. These researchinitiated connections perpetuate beyond these projects. This social capital may take the following forms:

Constructing/institutionalizing networks of research and development partners who interact with regard to resources (information, knowledge, funding).

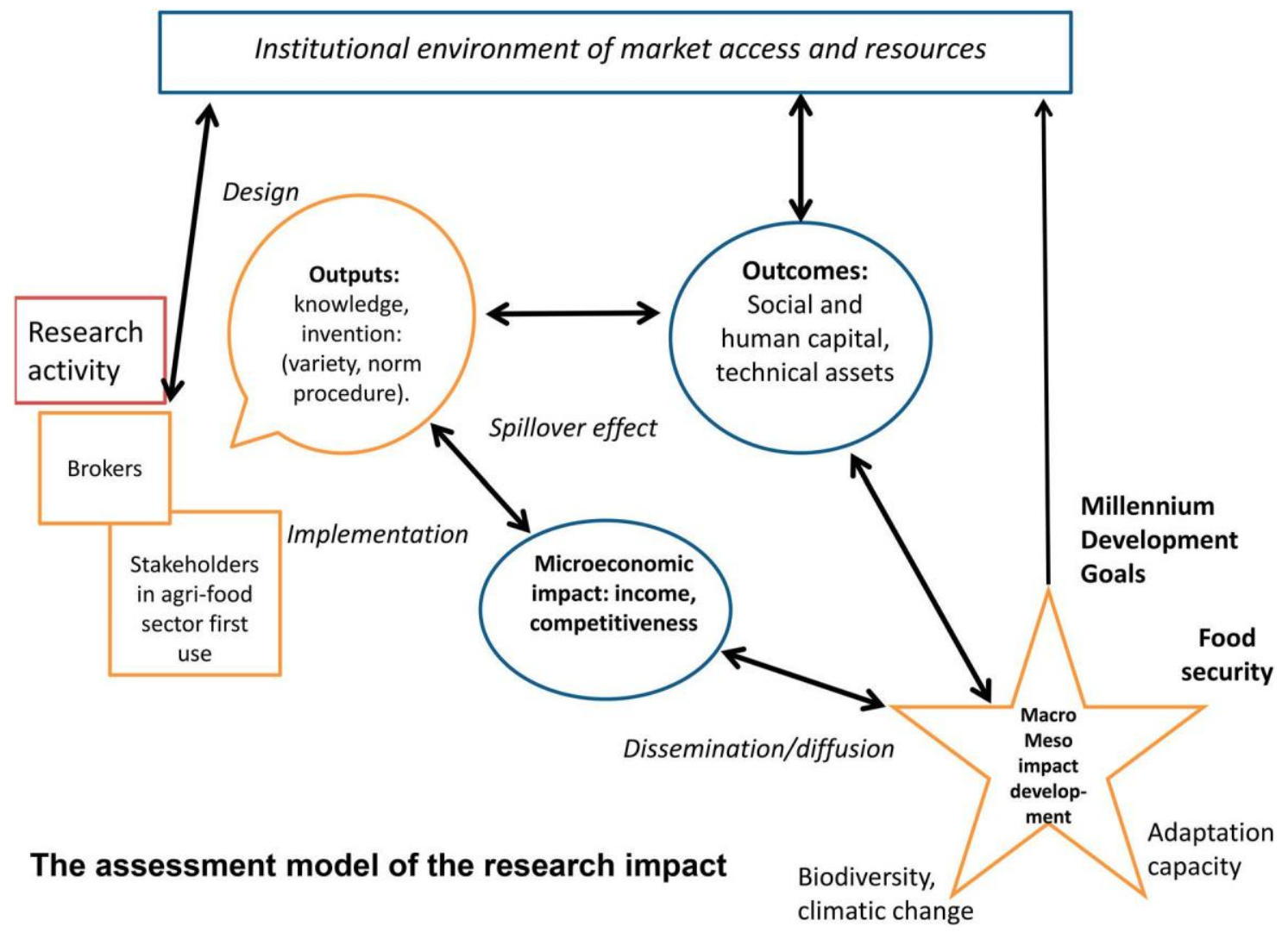

Figure 1: The assessment model of the research impact pathways.

Structuring national (Lundvall and Lemaapages 2014) impact institutional environments of innovation in terms of access to funding and markets. 
Emerging professional or 'intermediate' organizations and regional coordination mechanisms that generate coordination or collective actions (regional, national or sectoral).

Public/private partnership and, more generally, the mix of public and private resources; procurement and client networks in different types of institutional constructions (e.g. contractual relations).

Inter-professional organizations and regional coordination mechanisms; production and implementation of sanitary, social and regulatory standards.

\section{Contribution to human capital formation}

The creation and accumulation of human capital, as shown in the case studies, derive from different learning processes that accompany the implementation of research in partnerships or arise from this research (i.e., capacity building and training of different types of actors as well as other evolution in skills embedded into the innovation process) (Casadella, Liu, and Uzuni-dis 2015). Human capital constitutes a key asset in gen-erating future impacts (Kruss and Gastrow 2012). In the studied cases, human capital accumulation (skills, experience, knowledge) is shown together with inno-vation processes as part of three types of learning process configurations:

Individual training through the research of scientists and technicians from southern countries.

Collective professional training via learning situations in innovation processes within chains (experimenting agri-culturalist networks, entrepreneurs).

Academic training in university courses or specialized schools.

The setting up of human capital can either be an intentional or an indirect outcome of research development and innovation processes, and its effects are direct or indir-ect. Some take place upstream of innovation; others accompany or result from it. Human capital can be identified through various potentially measurable indicators, such as:

strengthening of the organizational skills of innovation system actors (e.g. producer organizations (PO) or outreach agents);

building farmers' capacities to assess innovation performance (diagnostic);

strengthening of collective and organizational skills (management, communication planning of PO and unions with a better understanding of producers' problems);

strengthening of producers' and POs' skills to interact with other actors of the innovation system (policymakers, businesses, market intermediaries, etc.); and capacity building of national research and training establishments (number of degree and non-degree courses, control of experimental protocols, analytical skills, pub-lications, etc.).

As an illustration, in the case of a mango varietal collection, learning related to grafting-on techniques led to the emergence of fruit plant nurseries that developed their own know-how on the domestication of local fruit plants like the African plum.

\section{Socio-technical assets}

Created and fuelled by research, these assets result from the connection made by human collectives through the knowledge they produce with material resources and tech-nical assets that this knowledge organizes and arranges. These can take several forms according to the type of research and innovations at stake, such as:

. variety collections or genetic sequence banks;

. serum banks for pathogens that form an integral part of epidemiological surveillance networks for animal diseases; and databases on farms.

They are activated as potential resources for innovation to meet needs, particularly in crisis situations.

The characterization of previous resources ends up revealing the intermediary functions of research and there-fore its role in activating interfaces between the actors in the innovation system (Table 3 ).

The intermediary role of researchers in partnerships and the changes produced

Characterizing the role of the different resources and assets described above leads to specifying another key dimension for understanding research impact on develop-ment, and therefore in innovation processes. This fourth dimension is the role of intermediation played by research in partnership in combining these different resources into specific configurations to trigger innovations and activate different interfaces between the actors in the innovation system.

This intermediation function corresponds to the integrating role of research in partnership between different social compartments:

among the worlds of production, exchange and use of products;

between research and development institutions (e.g. NGOs, POs) or businesses within local, national, regional and international areas;

in the complementarities among public sector policies (agricultural and research policies) or among research policies across scales (regional and national); and in the reality of disciplinary interfaces among biotechnical sciences, agronomy, humanities and social sciences.

This role of intermediation is even greater in southern countries, where institutional frameworks supporting innovation are sometimes deficient. This role contributes to ensuring the synergies and complementarities among the three types of capital. It also strengthens the capacities of different actors to mobilize new knowledge and inventions. 


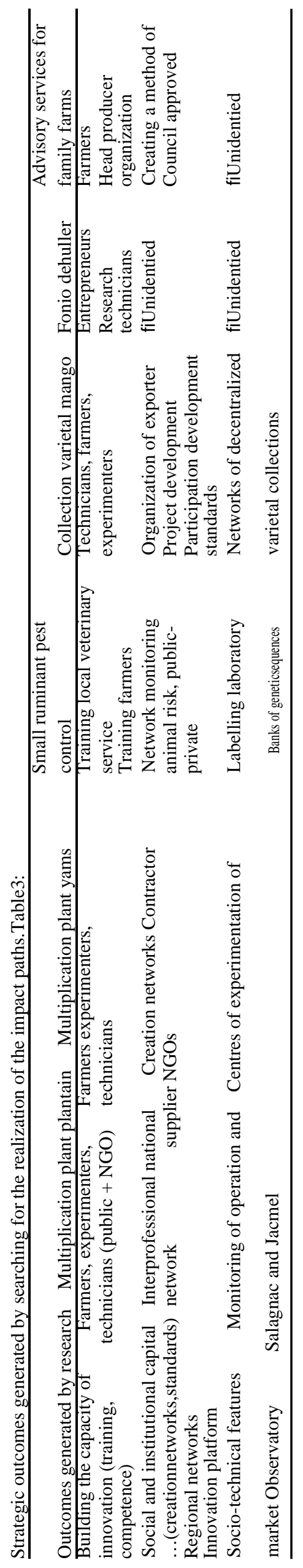

Conclusion

Quantitative methods of research IA raise methodological issues in their ability to take into account externalities in the long term and spillover effects. These methods are also questioned in relationship to their theoretical under-pinnings (i.e., the linear model of innovation and the exclusive reference to the substantive rationality of neo-classical economic rationality).

The evolution of the development challenges set by the Millennium Development Goals shapes the need for a transition in the technological paradigms in agriculture and food to better integrate environmental and social research questions, particularly the reduction of inequality in development between countries. These new needs require an adaptation and a diversification of the methodo-logical benchmarks to evaluate the relationships between research and development, as explored in this paper.

The first trajectory of adaptation extends and improves the methodological frameworks of quantitative approaches to measuring impact. It mobilizes experimen-tal approaches within the technical aims of demonstrating proof. It does little to explain the context of processes and hardly challenges the linear model of innovation, if at all.

The second trajectory does not set the goal of quantifying impact for prior intent. From the start, it considers the linear model of innovation as erroneous, and mobilizes a systemic and evolutionist analytical framework. It pro-poses to strengthen qualitative methods to characterize impact pathways. These methods explain institutional con-ditions in backing innovation processes in development. Research activity is constructed through social interactions that allow for a better understanding of localized develop-ment needs. Development indicators revealed by the research processes are a result to be constructed.

Applying this approach to six case studies in southern countries has confirmed many results that show such a systemic dimension of innovation. Understanding these effects along impact pathways brings to light the transver-sal resources that research generates. These resources are crucial in the critical phase of transforming outputs into outcomes. They consist of human capital, social capital and socio-technical assets. Together with this resource generation, research plays an intermediation role in the translation of research results into socially useful outputs.

As stressed in this article, approaches for research IA can take two trajectories. Methodological investment priority can be given to improving either the quantitative assessments of causalities between research and development or the qualitative approaches of systemic processes. Furthermore, the term 'development ' may not be per-ceived in the same way between the two trajectories. Attempts to hybridize these trajectories remain unconvin-cing for now (Ton 2012). However, as evident from this article, improving qualitative approaches will have to deal with better integrating measurement tools to describe the conditions needed for spillover effects and increased adoption returns. This would allow the relationship between outcomes and development to be better shown. We argue that this trajectory is better suited to renewing the technological paradigms of research in agriculture and diversifying the prospects of development based on 
societal needs. The results confirm the introductory hypothesis. Indeed, the methods for assessing the impact of research guide the trajectories of innovation. Therefore, monetary assessment methods are quantitative findings that do little to incorporate the long term or the external-ities. They direct innovation and development approaches on the use of research to increase short-term economic productivity.

The more qualitative methods for understanding systemic processes better account for the possible variability of research contributions (Avenier and Thomas 2015). They also channel innovation for building the development capacities of stakeholders, enabling people to adapt their innovation processes, which could be diversified in the long term and contingent upon social realities. The complementary hybridization occurring between these two methods is likely desirable.

These results call into question the terms of developing research and innovation policies (Wieczorek and Hekkert 2012). Concerning research policies, they highlight the need to change methodological frameworks to assess the causalities between research and development. In terms of development policies, the 'systemization' of causalities linking research activity and development renews the analytical frameworks that are mobilized to develop inno-vation policies.

\section{Notes}

1. Consulting Group on International Agricultural Research, advanced research centres, universities, national research institutions.

2. An analysis of case studies referenced by CGIAR research impact assessments shows a random sample of 15 articles; $75 \%$ of these case studies are of new varieties developed in research centres.

\section{References}

Alston, J. M., G. W. Norton, and P. G. Pardey. 1995. Science under Scarcity: Principles and Practice for Agricultural Evaluation and Priority Setting. New York: Cornell University Press.

Arega, D., R. Alene, C. Khataza, P. Chibwana, and Moyo Ntawuruhunga. 2013. "Economic Impacts of Cassava Research and Extension in Malawi and Zambia." Journal of Development and Agricultural Economics 5 (11): 4-57. doi:10.5897/JDAE2013.04.

Arza, V., and P. van Zwanenberg. 2014. "The Politics of Technological Upgrading: International Transfer to and Adaptation of GM Cotton in Argentina." World Development 59: 521-534.

Avenier, M. J., and C. Thomas. 2015. "Finding One's Way around Various Methodological Guidelines for Doing Rigorous Case Studies: A Comparison of Four Epistemological Frameworks." Systèmes d'information \& management 20: 61-98.

Berriet-Solliec, M., P. Labarthe, and C. Laurent. 2014. "Goals of evaluation and types of evidence." Evaluation 20 (2): 195-213.

Boyer, J., L. Temple, and R. Scutt. 2014. "Etude de cas: la technique Minisett en Haïti, une innovation co-construite entre chercheurs et producteurs dans le respect des conditions locales et des enjeux agro-écologiques." Field Actions Science Reports Special Issue 9 | 2014, Online since 27 December 2013. Accessed October 12 2016. http:// factsreports.revues.org/2779.
Bozeman, J. 2011. "Public Value Mapping and Science

Policy Evaluation." Minerva 49 (1): 1-23.

Callon, M., and D. Foray. 1997. "Introduction: Nouvelle économie de la Science ou socioéconomie de la recherche scientifique?" Economie industrielle 79: 13-35.

Carlson, B. 2006. "Internationalization of Innovation Systems: A Survey of the Literature." Research Policy 35: 56-67.

Casadella, V., Z. Liu, and D. Uzunidis. 2015. Innovation Capabilities and Economic Development in Open Economies. Paris: Collection Innovation Entrepreneuriat et gestion, ISTE.

Clark, N. 2002. "Innovation Systems, Institutional Change and The New Knowledge Market: Implications For Third World Agricultural Development." Economics of Innovation and New Technology 11 (4-5): 353-368.

De Bon, H., J. Huat, L. Parrot, A. Sinzogan, T. Martin, E. Malézieux, and J. F. Vayssières. 2014. "Pesticide Risks from Fruit and Vegetable Pest Management by Small Farmers in Sub-Saharan Africa. A Review." Agronomy for Sustainable Development 34: 723-736. doi:10.1007/ s13593-014-0216-7.

De Janvry, A., A. Dustan, and E. Sadoulet. 2011. Recent Advances in Impact Analysis Methods for Ex-post Impact Assessments of Agricultural Technology: Options for the CGIAR. Berkeley: University of California. $36 \mathrm{p}$.

Dorin, B., J. C. Hourcade, and M. Benoit-Cattin. 2012. "A World Without Farmers?? Food Production, Inclusive Development and Ecology: Historical Evidences for a New Deal." 12th Biennial Conference of the International Society for Ecological Economics, Brazil. 38 p.

Douthwaite, B., and M. Gummert. 2010. "Learning Selection Revisited: How can Agricultural Researchers make a Difference?" Agricultural Systems 103 (5): 245-255.

Duflo, E., R. Glennerster, and M. Kremer. 2006. "Using Randomization in Development Economics Research: A Toolkit." Technical "Working" Paper $n^{\circ}$ 333. http://www. nber.org/papers/t0333.

Dury, S., and L. Temple. 1999. "'Diversification of peri-urban small farms toward fruit production in Yaounde" (Cameroon): Consequences for the Development Process and Research. Jardin planétaire'99: actes." Chambery, France, Prospective 2100: 531-535.

Eisenhardt, K. M., and M. E. Grabner. 2007. "Théory Building from Cases: Opportunities and Challenges." Academy of Management Journal 50 (1): 25-32.

Fok, M., and N. Xu. 2010. "Libéralisation et régulation des marchés de variétés et de semences : analyse du coton-Bt en Chine et pays émergents." Cahiers Agriculture 19: 28-33.

Gaunand, A., A. Hocdé, S. Lemarié, M. Matt, and E. de Turckheimdai. 2015. "How does Public Agricultural Research Impact Society? A Characterization of Various pat-terns." Research Policy 44: 849-861.

Georghiou, F. 2011. "Introducing 'Productive Interactions' in Social Impact Assessment." Research Evaluation 20 (3): 211-218.

Glover, D., J. Sumberg, and J. A. Anderson. 2016. "The Adoption Problem; or why we Still Understand so Little about Technological chAnge in African Agriculture." Outlook on Agriculture 45 (1): 3-6.

Hall, A., V. Rasheed Sulaiman, C. Norman, and B. Yoganandn. 2003. "From Measuring Impact to Learning Institutional Lessons: An Innovation Systems Perspective on Improving the Management of International Agricultural Research." Agricultural Systems 78 (2): 213-241.

Heisey, P. W., and J. L. King, et al. 2010. "Assessing the Benefits of Public Research Within an Economic Framework. The Case of USDA's Agricultural Research Service." Economic Research Report: 95-82, Washington, USDA.

Joly, P-B., A. Gaunand, L. Colinet, P. Larédo, S. Lemarié, and M. Matt. 2015. "ASIRPA: A Comprehensive Theory-based Approach to Assessing the Societal Impacts of a Research Organization." Research Evaluation, 24 (4): 440-453. doi: 10.1093/reseval/rvv015. 
Kingwell, R. 1999. "Institutional and Social Influences on R\&D Evaluation in Agriculture." The Australian Journal of Agricultural and Resource Economics 43 (1): 115-128.

Klerkx, L., B. van Mierlo, and C. Leeuwis. 2012. "Evolution of Systems Approaches to Agricultural Innovation: Concepts, Analysis and Interventions." In Farming Systems Research into the 21st Century: The new dynamic, edited by I. Darnhofer, D. Gibbon, and B. Dedieu, 457-483. Netherlands: Springer.

Kruss, G., and M. Gastrow. 2012. "Global Innovation Networks, Human Capital, and Development." Innovation and Development, 2 (2): 205-208. doi:10.1080/2157930X. 2012.724885

Laperche, B. 2009. "Stratégies d'innovation des firmes des sciences de la vie et appropriation des ressources végétales: processus et enjeux." Mondes en développement 147: 109122.

Laperche, B., D. Uzunidis, and N.V. Tunzelmann. 2008. The Genesis of Innovation: Systemic Linkages Between Knowledge and the Market, 285. Cheltenham, UK; Northampton, MA: Edward Elgar Publishing.

Leeuwis, C., M. Schut, A. Waters-Bayer, R. Mur, K. Atta-Krah, B. Douthwaite, and L. van Veldhuizen. 2014. Capacity to innovate from a System CGIAR Research Program Perspective. Penang, Malaysia: CGIAR Research Program on Aquatic Agricultural Systems. Program Brief AAS-2014-29.

Lundvall, B. A., and R. Lemaapages. 2014. "Growth and Structural Change in Africa: Development Strategies for the Learning Economy." African Journal of Science, Technology, Innovation and Development 6 (5): 455-466. DOI:10.1080/20421338.2014.979660.

Maredia, M. K., and D. A. Raitzer. 2010. "Estimating Overall Returns to International Agricultural Research in Africa through Benefit-cost Analysis: A Best-evidence Approach." Agricultural Economics 41 (1): 81-100.

Matthew, L. W., and I. Rafols. 2015. "Research Portfolio Analysis in Science Policy: Moving from Financial Returns to Societal Benefits." Minerva 53: 89-115.

McIntyre, B. D., H. Herren, J. Wakhungu, and R. Watson. 2008. "Impacts of AKST on Development and Sustainability Goals." International Assessment of Agricultural Science and Technology for Development. New York: Island Press.

Mostafalou, S., and M. Abdollahi. 2013. "Pesticides and Human Chronic Diseases: Evidences, Mechanisms, and Perspectives." Toxicology and Applied Pharmacology 268: 157-177.

Naudet, J. D., J. Delarue, and T. Bernard. 2012. "Evaluations d'impact: un outil de redevabilitéles leçons tirées de l'expérience de l'AFD." Revue d'économie du développement 20: 27-48.

Nederlof, E. S., N. Roling, and A. van Huis. 2007. "Pathways for Agricultural Science Impact in West Africa: Lessons from the Convergence of Sciences Program." International Journal of agricultural sustainability 5: 247-264.

Nelson, P. R., and K. Nelson. 2002. "Technology Institutions, and Innovation Systems." Research Policy 31: 265-272.

Nyemeck, B. J., and G. B. Nkamleu. 2006. "Potentiel de Productivite et Efficacite Technique du Secteur Agricole en Afrique." Canadian Journal of Agricultural Economics/ Revue canadienne d'agroeconomie 54 (3): 361-377.

Omamo, S. W., and J. K. Lynam. 2003. "Agricultural Science and Technology Policy in Africa." Research Policy 32 (9): $1681-1694$
ONU. 2015. "The Millennium Development Goals." Report 2015, 73p

Pal, S. 2011. "Impacts of CGIAR Crop Improvement and Natural Resource Management Research: A Review of Evidence." Agricultural Economics Research Review 24: 185-200.

Parayil, G. 2003. "Mapping Technological Trajectories of the Green Revolution and the Gene Revolution from Modernization to Globalization." Research Policy 32 (6): 971-990.

Pietrobelli, C., and R. Rabelloti. 2011. "Global Value Chains Meet Innovation Systems: Are There Learning Opportunities for Developing Countries?" World Development 39 (7): 1261-1269.

Pretty, J., and H. Ward. 2001. "Social Capital and the Environment." World Development 29 (2): 209-227.

Renkow, M., and D. Byerlee. 2010. "The Impacts of CGIAR Research: A Review Of recent Evidence." Food Policy 35 (5): 391-402.

Röling, N. 2009. "Pathways for Impact: Scientists' Different Perspectives on Agricultural Innovation." International Journal of Agricultural Sustainability 7 (2): 83-94.

Sabourin, E. 2014. "Acesso aos mercados para a agricultura familiar: uma leitura pela reciprocidade e a economia solidaria." Rev Econ NE 45: 21-35

Sumberg, J., J. Thompson, and P. Woodhouse. 2013. "Why Agronomy in the Developing World has Become Contentious." Agriculture and Human Values 30: 71-83.

Temple, L., M. Kwa, J. Tetang, and A. Bikoï. 2011. "Organizational Determinant of Technological Innovation in Food Agriculture and Impacts on Sustainable Development." Agronomy for sustainable development 31 (4): 745-755.

Temple, L., J. M. Touzard, J. Boyer, and D. Requier Desjardins. 2015. "Comparaison des trajectoires d'innovation pour la sécurisation alimentaire des pays du Sud." Biotechnol. Agron. Soc. Environ 19 (1): 53-61.

Ton, G. 2012. "The Mixing of Methods: A Three-Step Process for Improving Rigour in Impact Evaluations." Evaluation 18 (1): 5-25.

Touzard, J. M., L. Temple, G. Faure, and B. Triomphe. 2015. "Innovation Systems and Knowledge Communities in the Agriculture and Agrifood Sector: A Literature Review." Journal of Innovation Economics and Management 17 (17): 117-142.

Vanloqueren, G., and P. V. Baret. 2009. "How Agricultural Research Systems Shape a Technological Regime that Develops Genetic Engineering but Locks out Agroecological Innovations." Research Policy 38: 971-983.

Walker, T., J. Ryan, and T. Kelley. 2010. "Impact Assessment of Policy-Oriented International Agricultural Research: Evidence and Insights from Case Studies." World Development 38 (10): 1453-1461.

Wieczorek, A. J., and M. P. Hekkert. 2012. "Systemic Instruments for Systemic Innovation Problems: A Framework for Policy Makers and Innovation Scholars." Science and Public Policy 39: 74-87.

Woodhouse, P. 2010. "Agricultural Research, Livelihoods and Poverty: Studies of Economic and Social Impacts in Six Countries - Edited by Michelle Adato and Ruth MeinzenDick." Journal of agrarian change 10 (2): 294-297.

Yin, R. K. 2014. Case Study Research: Design and Methods. London: SAGE. 